\title{
Current Status of Rotational Atherectomy in the Drug-Eluting Stent Era
}

\author{
Tadayuki Uetani, MD, PhD; Tetsuya Amano, MD, PhD
}

$\mathbf{J}$ arome Ritchie, David Auth, and colleagues were the first to treat obstructive coronary disease using rotational atherectomy (RA) in 1987, approximately 30 years ago. ${ }^{1}$ Since then, RA has been widely used to modify lesion properties in patients with coronary atherosclerosis, including those of severely calcified lesions, in which balloon and stent delivery, as well as lesion expansion and stent placement, are difficult to complete.

Despite the efficacy of this device, its use in rotating a diamond-tipped burr with a diameter of $1.25-2.5 \mathrm{~mm}$ in a coronary artery at 140,000-200,000 rpm can cause severe complications, such as coronary perforation and slow or absent reflow from micro-embolization caused by crushed debris. For this reason, the use of this equipment requires additional training beyond that required to perform percutaneous coronary intervention (PCI).

In addition, the increased incidence of vascular complications and PCI-associated stroke, compared with ordinary PCI, associated with the use of larger guiding catheters or vascular access introducers also requires attention. Attempts have been made to reduce these complications through the use of transradial access and smaller guiding catheters, but RA using smaller size catheters is disadvantageous in dealing with complications, such as coronary perforation and burr entrapment. ${ }^{2}$

For several years after RA was introduced, there have been problems with high restenosis rates related to the use of RA and bare metal stents. Recently, drug-eluting stent (DES) implantation following RA has resulted in reductions of restenosis and target lesion revascularization (TLR). ${ }^{3}$ Using a large-size burr and more aggressively removing plaque as a "non-stenting strategy" could increase the risk of complications. Consequently, RA has been used mainly as a lesion modification technique, particularly in severe calcified lesions, resulting in the safe implantation of DES or comparable devices.

In this issue of the Journal, Jinnouchi and colleagues ${ }^{4}$ report the results of cases from 11 to 6 years ago in which patients underwent DES implantation following RA in a Japanese large-scale PCI center. Notably, this technique made use of 2nd-generation DES (biolimus-eluting stents and everolimus-eluting stents) in more than half of the patients, while the other half were treated with 1st-generation DES. Yet, because this report was observational,

\section{Article p 983}

rather than prospective and randomized, some aspects require further consideration.

The most important thing to note is that this research adopted TLR as a major outcome. Although the indications for TLR are described in the report, only $57 \%$ of cases of ischemia-driven (ID) TLR at 1 year were proven to be functional ischemic findings, while approximately $30 \%$ of all TLR cases (ID+non-ID-TLR) were found to not be ID. That is, the majority of cases of TLR in the study were performed on the basis of so-called "routine follow-up angiography" and based on the judgement of clinicians.

The COURAGE trial published in 2007 during this research period proved the limits of PCI in stabilizing coronary artery disease (CAD) in a large-scale trial, and the FAME study in 2009 confirmed that performing PCI for a coronary lesion without functional ischemia is useless. ${ }^{\mathbf{5}, \mathbf{6}}$ These findings have considerably affected the perceived indications for PCI among interventional cardiologists. In this context, it is possible that some of the cases of TLR in the second half of the study (2nd-DES era) might have been postponed because of the absence of functional ischemic findings.

Even after considering these matters, the present study reports extensive differences in the incidence of TLR between stents of both generations. In particular, 2nd-DES have found to be advantageous in many studies, with implantation of a 2nd-DES after RA believed to be a more effective treatment option. Moreover, 2nd-DES make use of an improved drug and polymer formulation, a thinner strut compared with 1st-DES, and greater capacity for expansion within the lesion after RA. These changes may contribute to a decreased incidence of TLR.

However, the higher incidence of procedural-related complications is the biggest concern for RA. The incidence of coronary perforation in this study was considerably higher $(2.3 \%)$ than previously reported for ordinary PCI $(0.3-0.7 \%)$, even after considering that it covers complex cases. Moreover, in another Japanese multicenter registry of RA, a higher incidence of in-hospital death, cardiac tamponade, and emergency surgery was reported $(3.0 \%$, $0.9 \%$, and $0.6 \%$, respectively). ${ }^{7}$

The opinions expressed in this article are not necessarily those of the editors or of the Japanese Circulation Society.

Received February 7, 2018; accepted February 12, 2018; released online March 8, 2018

Internal Medicine, Uetani Medical Office, Nagoya (T.U.); Department of Cardiology, Aichi Medical University, Nagakute (T.A.), Japan

Mailing address: Tadayuki Uetani, MD, PhD, Internal Medicine, Uetani Medical Office, 1-14-1 Sakuradai, Minami-ku, Nagoya 457-0005, Japan. E-mail: contact@uetani-clinic.com

ISSN-1346-9843 All rights are reserved to the Japanese Circulation Society. For permissions, please e-mail: cj@j-circ.or.jp 
One recent double-blind study indicated that PCI for patients with stable angina is not effective in improving duration of exercise and extending relief from angina when compared with sham-procedure. Considerable evidence demonstrates that PCI is not superior to other, high performance medical therapies or even sham-procedures when considering "hard endpoints" or an improvement in quality of life. Thus, it is important to clarify that PCI is indicated only in limited cases of stable angina in patients with obstructive coronary disease..$^{89}$ Despite having been introduced over 30 years ago, there has been few improvements in RA methods and so it is difficult to perform PCI in compliance with the strict safety requirements for modern elective PCI in stable angina patients.

Therefore, it appears that a global decline in elective PCI cases and stricter demands for safety of PCI will further reduce the already uncommon cases of RA. In a recent report from a Japanese PCI registry, approximately $40 \%$ of all RA cases were performed in low-volume institutions ( $<24$ cases/2 years) and the institutional volume of RA cases was inversely associated with worse outcomes. ${ }^{10}$ Therefore, RA should be performed in only select facilities that employ medical staff who are familiar with complex PCI. It appears that increasing the number of reports from high-volume facilities, such as those reported herein, are necessary for the safer and more effective use of any device.

\section{Disclosures}

There is no conflict of interest.

\section{References}

1. Ritchie JL, Hansen DD, Intlekofer MJ, Hall M, Auth DC.
Rotational approaches to atherectomy and thrombectomy. $Z$ Kardiol 1987; 76(Suppl 6): 59-65.

2. Watt J, Austin D, Mackay D, Nolan J, Oldroyd KG. Radial versus femoral access for rotational atherectomy: A UK observational study of 8622 patients. Circ Cardiovasc Interv 2017; 10: e005311.

3. Tamura H, Miyauchi K, Dohi T, Tsuboi S, Ogita M, Kasai T, et al. Comparison of clinical and angiographic outcomes after bare metal stents and drug-eluting stents following rotational atherectomy. Int Heart $J$ 2016; 57: 150-157.

4. Jinnouchi H, Kuramitsu S, Shinozaki T, Hiromasa T, Kobayashi Y, Takeji Y, et al. Five-year clinical outcomes after drug-eluting stent implantation following rotational atherectomy for heavily calcified lesions. Circ J 2018; 82: 983-991.

5. Boden WE, O'Rourke RA, Teo KK, Hartigan PM, Maron DJ, Kostuk WJ, et al; COURAGE Trial Research Group. Optimal medical therapy with or without PCI for stable coronary disease. N Engl J Med 2007; 356: 1503-1516.

6. Tonino PA, De Bruyne B, Pijls NH, Siebert U, Ikeno F, van't Veer M, et al; FAME Study Investigators. Fractional flow reserve versus angiography for guiding percutaneous coronary intervention. N Engl J Med 2009; 360: 213-224.

7. Okai I, Dohi T, Okazaki S, Jujo K, Nakashima M, Otsuki H, et al. Clinical characteristics and long-term outcomes of rotational atherectomy: J2T Multicenter Registry. Circ J 2018; 82: 369375 .

8. Fearon WF, Nishi T, De Bruyne B, Boothroyd DB, Barbato E, Tonino $\mathrm{P}$, et al. Clinical outcomes and cost-effectiveness of fractional flow reserve-guided percutaneous coronary intervention in patients with stable coronary artery disease: Three-year follow-up of the FAME 2 Trial. Circulation 2018; 137: 480-487.

9. Al-Lamee R, Thompson D, Dehbi HM, Sen S, Tang K, Davies J, et al; ORBITA investigators. Percutaneous coronary intervention in stable angina (ORBITA): A double-blind, randomised controlled trial. Lancet 2018; 391: 31-40.

10. Sakakura K, Inohara T, Kohsaka S, Amano T, Uemura S, Ishii $\mathrm{H}$, et al. Incidence and determinants of complications in rotational atherectomy: Insights from the National Clinical Data (J-PCI Registry). Circ Cardiovasc Interv 2016; 9: e004278. 